\title{
Evaluation of Models for Alternaria Brown Spot of Mandarin Under Mediterranean Conditions by Partial Receiver Operating Characteristic Curve Analysis
}

\author{
Daniel D. M. Bassimba, Jose L. Mira, and Antonio Vicent
}

First author: Instituto de Investigação Agronómica (IIA), Chianga, 2104 Huambo, Angola; second and third authors: Centro de Protección Vegetal y Biotecnología, Instituto Valenciano de Investigaciones Agrarias (IVIA), Moncada, 46113 Valencia, Spain. Accepted for publication 25 January 2017.

\begin{abstract}
Alternaria brown spot (ABS) is a serious fungal disease of mandarin in the Mediterranean Basin. Due to the rigorous fruit quality standards, models for ABS should avoid false negatives. Experiments were conducted with susceptible 'Fortune' and 'Nova' inoculated at different temperatures and leaf wetness durations, including interrupted periods. Effects of temperature and time elapsed after inoculation were also studied. Disease incidence data were fitted to generalized additive models and a generic infection model. Exposure of trap plants in affected orchards was used for model evaluation, including the Alter-Rater and a simple rule system (SRS). The predictive

ability of the models was analyzed using the partial area under the receiver operating characteristic curve in the high-sensitivity range between 0.9 and 1. Postinoculation temperature had a significant effect on disease incidence, with maximum symptom expression after $30 \mathrm{~h}$ on Fortune and $60 \mathrm{~h}$ on Nova. ABS incidence did not increase after a leaf wetness interruption of $1 \mathrm{~h}$ on Nova and $2 \mathrm{~h}$ on Fortune. All the models evaluated had high falsepositive rates on Fortune. Only the SRS showed a substantial strength of agreement in Nova, with a true-positive rate of 0.93 and false-positive rate of 0.16 .
\end{abstract}

Alternaria brown spot (ABS) is a serious disease of mandarin (Citrus reticulata Blanco) and its hybrids in the Mediterranean Basin and other semiarid citrus areas. Severe epidemics have been also reported in humid subtropical citrus areas, including Florida (United States), Brazil, Argentina, and Colombia (Timmer et al. 2003). The disease affects susceptible mandarin cultivars such as 'Dancy', 'Emperor', 'Ponkan', and their hybrids. Symptoms of ABS consist of necrotic lesions on fruit and leaves, with premature fruit drop and leaf abscission. Mandarin production in the Mediterranean Basin is mostly targeted for fresh fruit export and has to comply with rigorous international quality standards (OECD 2010); therefore, the emergence of ABS had a serious negative impact for some mandarin cultivars in this area. Just in the Comunitat Valenciana region, the main citrusgrowing area in the Mediterranean Basin, the production of the highly susceptible 'Fortune' declined due to ABS from 160,000 to 21,000 t since the time of the first disease outbreak in 1998 to 2012. Meanwhile, the moderately susceptible 'Nova' remained constant approximately 130,000 t (Anonymous 2012).

The ABS pathogen has been referred to as the "tangerine pathotype" of Alternaria alternata (Fr.) Keissl. (Stewart et al. 2014). This fungal pathogen produces the ACT host-specific toxin (HST), which affects only a restricted number of mandarin cultivars (Timmer et al. 2003). The pathogen reproduces asexually by means of conidia formed in lesions on leaves, twigs, and fruit (Reis et al. 2006). Conidia are dispersed by wind and splashed by rain, infecting young shoots and fruit under warm conditions and relatively long leaf wetness duration (LWD) (Canihos et al. 1999; Timmer et al. 1998). Due to the effect of the ACT toxin, the incubation period of the ABS pathogen is very short (Timmer et al. 2003). Studies in Florida and Spain indicated that inoculum was broadly distributed in the orchards throughout the growing season and was not considered a limiting factor for disease development (Bassimba et al. 2014; Timmer et al. 1998, 2000). The

Corresponding author: A. Vicent; E-mail address: vicent_antciv@gva.es

(c) 2017 The American Phytopathological Society incidence and severity of ABS is mostly influenced by periods of host susceptibility and weather conditions favorable for infection (Bassimba et al. 2014). In Spain, leaves acquire ontogenic resistance to ABS when they are fully expanded but fruit are always susceptible (Vicent et al. 2004). Under these conditions, infections by the ABS pathogen are restricted to favorable periods and disease onset is strongly influenced by rainfall and temperature (Bassimba et al. 2014).

Between 3 and 10 fungicide sprays per year are applied for ABS management in affected areas in Florida, Brazil, and Spain (Bhatia et al. 2003; Peres and Timmer 2006; Vicent et al. 2007). Due to the short incubation period of the ABS pathogen, applications of curative fungicides are ineffective. The management of ABS depends mostly on the protective action of the fungicides and their efficacy strongly depends on the synchrony between fungicide application and infection periods (Vicent et al. 2007). With the use of predictive models, it is possible to estimate disease risk and devise more efficient fungicide spray programs, protecting the trees during infection periods but avoiding unnecessary applications (De Wolf and Isard 2007). The Alter-Rater model was developed for ABS management in Florida based on field studies and experiments conducted under controlled conditions (Canihos et al. 1999; Timmer et al. 1998, 2000). The performance of the Alter-Rater to estimate the risk of ABS and improve fungicide schedules was successfully evaluated in Florida and Brazil (Bhatia et al. 2003; Peres and Timmer 2006). However, considering the climatic differences between humid subtropical and semiarid regions, the performance of the Alter-Rater model cannot be directly extrapolated to Spain or other Mediterranean countries.

The analysis of receiver operating characteristic (ROC) curves is one of the most popular methods for evaluating disease models used for binary classification (Dewdney et al. 2007; Gent and Ocamb 2009; Makowski et al. 2005; Metz 1978; Turechek and Wilcox 2005; Twengström et al. 1998; Yuen et al. 1996). In contrast to overall model fit indices, ROC analysis includes explicit evaluation of inaccurate decisions, either false positives or false negatives. Sensitivity is defined as the proportion of true positives and specificity as the proportion of true negatives predicted by the model. Typically, ROC curves display the false-positive rate (i.e., 1-specificity) and true-positive rate values 
associated with all the possible cut-off thresholds of the model output, from which the modeler can select an optimal threshold to minimize one or both sources of error (Madden et al. 2007; Youden 1950). False positives will be obtained with a cut-off threshold of low specificity, resulting in unnecessary fungicide sprays, but some infections will be missed with a cut-off threshold of low sensitivity due to false negatives. According to international quality standards, the presence of just two ABS lesions per fruit reduces the commercial value and fruit with more than six necrotic spots are out of grade (OECD 2010). Because of these rigorous export quality criteria for ABS, citrus growers in Spain are reluctant to change from routine calendar sprays to model-driven fungicide schedules because of their perceptions of risk. To facilitate the adoption of predictive systems for ABS, the sensitivity of the models must be extremely high to avoid false negatives.

The total area under the ROC curve (AUC) is a widely used index of model performance which can be defined as the integrated 1-specificity over all sensitivity values (Metz 1978). Nevertheless, only those cut-off thresholds of the model yielding a low rate of false negatives are acceptable for ABS management. In these situations, the total AUC may not be a meaningful summary of model performance and might lead to the selection of inappropriate cut-off thresholds. A potential solution is to focus the analysis on the partial AUC (pAUC), which is defined as an integration of an ROC curve over a confined range of sensitivity (or specificity) and can be used to select models that satisfy this prerequisite condition. Although partial ROC curve analysis has been used extensively in other research areas, applications to plant disease models were not found (Jiang et al. 1996; McClish 1989; Wang and Chang 2011).

Considering that models for ABS were not previously evaluated in semiarid areas and a low rate of false negatives is critical for model adoption by citrus producers, the objectives of this study were to (i) develop models for ABS by assessing the effect of temperature on the incubation period, and modeling disease incidence in plants inoculated under different combinations of temperature and LWD, including interrupted periods; and (ii) evaluate models for ABS on the highly susceptible Fortune and moderately susceptible Nova by partial ROC curve analysis.

\section{MATERIALS AND METHODS}

Laboratory experiments. A virulent single-spore isolate of A. alternata (IVIA-A005) isolated from an infected Fortune fruit in Valencia (Spain) was used for laboratory experiments. The isolate was stored in $15 \%$ glycerol at $-80^{\circ} \mathrm{C}$ in $1.5-\mathrm{ml}$ cryovials. The vials were defrosted at $34^{\circ} \mathrm{C}$ for $30 \mathrm{~min}$ and the fungus was transferred to Petri dishes with potato dextrose agar (PDA) and maintained at $25^{\circ} \mathrm{C}$ in darkness for 7 days. A stock suspension containing mycelium and conidia was prepared by pouring sterile water over the colonies and gently rubbing the surface with a sterile glass rod, then maintained at $4^{\circ} \mathrm{C}$. PDA dishes were seeded by spreading $1-\mathrm{ml}$ aliquots of the stock suspension and placed under a photoperiod of $12 \mathrm{~h} /$ day and $12 \mathrm{~h} / \mathrm{night}$ (PhilipsTLD18W/33) at $25^{\circ} \mathrm{C}$ for 3 to 4 days. Conidial suspensions were obtained from cultures flooded with distilled water amended with $0.1 \%$ Tween 20 and were filtered through two layers of cheesecloth. Spore concentrations were adjusted to $10^{5}$ conidia $/ \mathrm{ml}$ with a hemocytometer and suspensions with less than $90 \%$ germination of conidia were discarded (Vicent et al. 2007).

Plant material used for laboratory experiments consisted of 2-year-old trees grafted on 'Carrizo' citrange grown in plastic pots $(250 \mathrm{~mm}$ in diameter by $200 \mathrm{~mm}$ deep) containing potting mix (75\% peat and $25 \%$ sand [ $\mathrm{vol} / \mathrm{vol}]$ ). The highly susceptible Fortune and moderately susceptible Nova were used in all experiments. Plants were fertilized weekly with a $0.1 \%$ solution of $14-10-14$ (N-P-K) with micronutrients. Trees were pruned completely to force growth of new shoots, which were inoculated using the conidial suspension as above when they were approximately $50 \%$ expanded, so that at least 100 leaves were susceptible to ABS (Vicent et al. 2004). In all experiments, three replications of three plants each were used for each treatment. Experiments were repeated once.
The effect of temperature on the incubation period (i.e., from inoculation to lesion development) of ABS was evaluated. Plants of both cultivars were inoculated by spraying a conidial suspension of the pathogen, using approximately $15 \mathrm{ml} /$ plant. Inoculated plants were immediately covered with black plastic bags and placed into growth chambers (Binder KB400; GE) at $20^{\circ} \mathrm{C}$ and LWD of $12 \mathrm{~h}$. Bags were removed and plants were dried with a fan, then maintained in growth chambers at $15,20,25$, or $30^{\circ} \mathrm{C}$. Disease incidence (i.e., proportion of affected leaves) was evaluated after 15, 17, 22, 40, and $50 \mathrm{~h}$ on all leaves.

The effects of temperature and LWD on ABS incidence were evaluated on both cultivars. Plants were inoculated as described above, with different temperature and LWD combinations: 10 or $35^{\circ} \mathrm{C}$ for 10 , 24 , or $48 \mathrm{~h} ; 8,12,17,22,27$, or $32^{\circ} \mathrm{C}$ for 8,16 , or $38 \mathrm{~h}$; and $15,20,25$, or $30^{\circ} \mathrm{C}$ for $8,10,16,24,38$, or $48 \mathrm{~h}$. Plastic bags were removed after the corresponding LWD period and plants were dried with a fan, then maintained in a separate growth chamber at approximately $23^{\circ} \mathrm{C}$ and $60 \%$ relative humidity $(\mathrm{RH})$. Disease incidence was evaluated on alternating days for 1 week.

The performance of the ABS pathogen under interrupted LWD was evaluated in both cultivars. Plants were inoculated as described above with an initial LWD of $12 \mathrm{~h}$ at $20^{\circ} \mathrm{C}$, after which the bags were removed and plants were dried with a fan. After a dry period of 1,2 , or $6 \mathrm{~h}$ in the dark at $65 \% \mathrm{RH}$, plants were misted again with sterile distilled water and bagged for $8 \mathrm{~h}$. Finally, the plants were dried again and moved to a separate growth chamber at approximately $23^{\circ} \mathrm{C}$ and $60 \%$ RH. Treatments consisting of 12 or $20 \mathrm{~h}$ of continuous LWD served as standards. Disease incidence was evaluated on alternating days for 1 week.

Field experiments. Studies were conducted in three orchards severely affected by ABS in Valencia province (Spain): two commercial orchards at Alzira and Chiva and an experimental orchard at Moncada. The orchard at Alzira had a plot size of $0.17 \mathrm{ha}, 5-\mathrm{m}$ across-row spacing, and 4-m in-row spacing, with a north-south row orientation. The orchard at Chiva had a plot size of 2.89 ha, 6-m across-row spacing, and 5 -m in-row spacing, with a north-south row orientation. The orchard at Moncada had a plot size of $0.72 \mathrm{ha}, 3-\mathrm{m}$ across-row spacing, and 2-m inrow spacing, with east-west row orientation. The orchard at Alzira was planted with Nova, the orchard at Chiva with Fortune, and the orchard at Moncada with mandarin hybrids obtained from crosses with Fortune and 'Minneola'. All trees were grafted on Carrizo citrange rootstock and were 15 years old at the end of the field experiments in 2013. Orchards were drip irrigated and crop management followed recommended practices. Copper oxychloride and mancozeb were applied in commercial orchards at Alzira and Chiva. Four and eight sprays with copper oxychloride and mancozeb were applied yearly in the commercial orchards at Alzira and Chiva, respectively. Fungicides were not applied in the experimental orchard at Moncada.

Environmental data were monitored hourly in the orchards with automated meteorological stations (Hobo U30; Onset Computer Corp.), including sensors for air temperature and ambient RH (Hobo S-THB; accuracies $\pm 0.2^{\circ} \mathrm{C}$ and $\left.\pm 2.5 \% \mathrm{RH}\right)$, rainfall (7852, resolution $0.2 \mathrm{~mm}$; Davis Instruments Corp.), LWD (Hobo S-LWA, resolution 0.59\%), and wind speed (Hobo S-WSA, accuracy $\pm 1.1 \mathrm{~m} / \mathrm{s}$ ). Environmental monitors were located within the row in the experimental area at the site of a missing tree. Data were collected at approximately $1.5 \mathrm{~m}$ above the soil surface, in the top one-quarter of the canopy height. Sensors of LWD were placed with a northerly exposure and fixed at a $30^{\circ}$ angle from the horizontal. A dry/wet cut-off point of 75.8 was selected within the 0-to-100 range, based on previous calibrations of the LWD sensors (Bassimba et al. 2017).

Infection periods were monitored weekly from September 2012 to December 2013 in the orchard at Alzira $(n=64)$, from October 2012 to December 2013 in the orchard at Chiva $(n=60)$, and from March 2011 to December 2013 in the orchard at Moncada $(n=142)$ by placing three trap plants of Fortune and three of Nova each week (Magarey and Sutton 2007). Plants were prepared as described in the laboratory data section and were $1.5 \mathrm{~m}$ tall when placed in the field. In the two 
commercial orchards, trap plants were placed between two trees and protected with a plastic sheet during fungicide spray applications. After a 7-day exposure, trap plants were returned to a growth chamber at approximately $23^{\circ} \mathrm{C}$ and disease incidence was evaluated on alternating days for 1 week.

Models. In each case, data from two corresponding experiments were combined after confirming the homogeneity of variances by Bartlett's test. R software v.3.1.0 was used in all of the analyses ( $R$ Core Team 2013). Disease incidence in Fortune and Nova plants under different temperatures and incubation times after inoculation were analyzed by a generalized additive model (GAM) (Wood 2006). GAM are semiparametric extensions of generalized linear models (GLM) with a linear predictor involving a sum of smooth functions of the covariates. In the same way as GLM, GAM incorporate a link function to establish a relationship between the mean of the response variable and the smoothed functions of the covariates. GAM are particularly suited when the relationships between the response variable and the covariates are highly nonlinear. The models used here incorporated a binomial error with a logit link function to estimate response curves with temperature and time after inoculation as covariates:

$$
\operatorname{logit}\left(\pi_{i}\right)=f_{1}\left(T_{i}\right)+f_{2}\left(I_{i}\right) \quad D_{i} \sim \operatorname{Binomial}\left(n_{i}, \pi_{i}\right)
$$

where $D=$ number of affected leaves in replicate $i, n=$ number of leaves in replicate $i, \pi=$ proportion of affected leaves in replicate $i$, $T=$ temperature $\left({ }^{\circ} \mathrm{C}\right), I=$ incubation time (h), and $f_{1}$ and $f_{2}$ are smooth functions based on cubic splines. The proportion of deviance accounted for by the model and the root mean square error (RMSE) were obtained. The package $\mathrm{mgcv}$ for $\mathrm{R}$ was used in the analysis (Wood 2006).

Disease incidence in Fortune and Nova plants inoculated under different temperature and LWD combinations was analyzed using a GAM with a binomial error and a logit link function (Wood 2006) to estimate response curves with temperature and LWD as covariates:

$$
\operatorname{logit}\left(\pi_{i}\right)=f\left(T_{i} W_{i}\right) \quad D_{i} \sim \operatorname{Binomial}\left(n_{i}, \pi_{i}\right)
$$

where $D=$ number of affected leaves in replicate $i, n=$ number of leaves in replicate $i, \pi=$ proportion of affected leaves in replicate $i, T=$ temperature $\left({ }^{\circ} \mathrm{C}\right), W=\mathrm{LWD}(\mathrm{h})$, and $f$ is a two-dimensional smooth function. The proportion of deviance accounted for by the model and RMSE were obtained.

The generic infection model (GIM) developed by Magarey et al. (2005) was also fitted to the data obtained in plants inoculated under different temperature and LWD combinations. This model estimates the LWD required to achieve a predefined disease incidence level at a given temperature which, in our study, was set just to disease presence. The LWD requirement in hours $\left(W_{(T)}\right)$ for the predefined disease incidence level at temperature $T$ is estimated from a temperature response function $\left(f_{(T)}\right)$ :

$$
\begin{gathered}
W_{(T)}=W_{\min } / f_{(T)} \leq W_{\max } \\
f_{(T)}=\left(\frac{T_{\max }-T}{T_{\max }-T_{o p t}}\right)\left(\frac{T-T_{\min }}{T_{o p t}-T_{\min }}\right)^{\left(T_{o p t}-T_{\min }\right) /\left(T_{\max }-T_{o p t}\right)}
\end{gathered}
$$

where $T=$ mean temperature $\left({ }^{\circ} \mathrm{C}\right)$ during leaf wetness period, $T_{\min }=$ minimum temperature for infection, $T_{o p t}=$ optimal temperature for infection, $T_{\max }=$ maximum temperature for infection (being $T_{\min } \leq T \leq$ $T_{\max }$ and 0 otherwise), $W_{\min }=$ the minimum value of $L W D$ requirement (h) for the predefined disease incidence level at any temperature, and $W_{\text {max }}$ provides an upper boundary on the value of $W_{(T)}$.

To deal with the limited amount of data, parameter values of the GIM were estimated using approximate Bayesian computation (ABC). Like other Bayesian methods, posterior probability distributions of the model parameters were estimated considering the prior distributions and experimental data but $\mathrm{ABC}$ was implemented without likelihood function (Makowski et al.2011). Prior distributions of the five model parameters were initially assumed to be uniform (U), with lower and upper limits (in parentheses) defined based on the values reported by Magarey et al. (2005) for a series of foliar fungal pathogens: $T_{\min } \sim \mathrm{U}(1,13.3), T_{\text {opt }} \sim \mathrm{U}(8.5,28), T_{\max } \sim \mathrm{U}(18,35)$, $W_{\text {min }} \sim \mathrm{U}(2,48)$, and $W_{\max } \sim \mathrm{U}(6,96)$. Due to the overlap of these initial distributions, constraints were established for the simulated prior distributions to satisfy $T_{\max }>T_{o p t}>T_{\min }$ and $W_{\max }>W_{\text {min }}$ (Makowski et al. 2011). Possible ranges of values of $W_{(T)}$ were derived from the laboratory experiments, where plants of Fortune and Nova were inoculated under different temperature and LWD combinations. Lower and upper bounds for the minimum LWD required for ABS presence $\left(W_{(T)}\right)$ in Fortune were 10 and $24 \mathrm{~h}$ for $10^{\circ} \mathrm{C} ; 4$ and $8 \mathrm{~h}$ for 12 , $15,17,20,22,25$, or $27^{\circ} \mathrm{C} ; 10$ and $16 \mathrm{~h}$ for $30^{\circ} \mathrm{C}$; and 10 and $24 \mathrm{~h}$ for $35^{\circ} \mathrm{C}$. The same lower and upper bounds for $W_{(T)}$ were set in Nova except for 6 and $10 \mathrm{~h}$ for $30^{\circ} \mathrm{C}$ and none for $35^{\circ} \mathrm{C}$. In total, 50,000,000 Monte Carlo simulations were performed using the rejection algorithm by Marjoram et al. (2003), as implemented by Makowski et al. (2011). In total, 1,476 simulations were accepted by the algorithm in Fortune and 3,947 in Nova, from which the median and the interval between the 5 and 95 percentiles (i.e., 90\% credible intervals) were obtained for each parameter. The RMSE of the GIM with the estimated median values for the parameters was also calculated.

In the model of Magarey et al. (2005), the additivity of two wet periods was conditioned by the critical dry-period interruption parameter $D_{50}$, defined as the duration of a dry period at $\mathrm{RH}<95 \%$ that will result in a $50 \%$ reduction in disease compared with a continuous leaf wetness period. Based on the interrupted LWD study described before, disease incidence obtained for each cultivar in the interrupted LWD treatment was compared by a one-tailed $t$ test with one-half of the disease incidence in the continuous LWD treatment of $20 \mathrm{~h}$. As a result, a value of $D_{50}=2 \mathrm{~h}$ and $D_{50}=1 \mathrm{~h}$ was fixed for Fortune and Nova, respectively.

The Alter-Rater model for ABS was also evaluated. This model assigns a point value from 0 to 11 to each day based on three weather factors: (i) rainfall greater or less than $2.5 \mathrm{~mm}$, (ii) LWD greater or less than $10 \mathrm{~h}$, and (iii) average daily temperature below $20^{\circ} \mathrm{C}$, between 20 and $28^{\circ} \mathrm{C}$, or greater than $28^{\circ} \mathrm{C}$ (Table 1). Daily point values are accumulated until a predefined trigger value for fungicide application is reached (Bhatia et al. 2003; Timmer et al. 2000).

A simple rule system (SRS) based on the previous studies on the epidemiology of ABS under semiarid conditions was also assessed (Bassimba et al. 2014). The SRS considers as the minimum requirements for disease onset an average weekly temperature $\left(T_{\text {week }}\right)$ of at least $12^{\circ} \mathrm{C}$ together with an accumulated weekly rainfall $\left(R_{\text {week }}\right)$ of at least $2 \mathrm{~mm}$. When these two criteria are met, a disease risk index was calculated as the resulting value of $T_{\text {week }}+R_{\text {week }}$, and is zero otherwise.

Partial ROC curve analysis. Model performance was evaluated using the disease incidence in trap plants and environmental data obtained in the field studies described above. In each orchard, weekly exposure periods of Fortune and Nova were classified as ABS present or absent ( 1 or 0 , respectively) based on the observation of symptoms on trap plants ( $>0 \%$ of affected leaves). All LWD and corresponding average temperatures were calculated in each week. GAM and GIM were run with these data and the outputs obtained were accumulated for each weekly exposure period. Alter-Rater scores were assigned daily (Table 1) and were accumulated for each week. The SRS was calculated based on $T_{\text {week }}$ and $R_{\text {week }}$ values for each week. To account for a possible differential effect of rain and dew on ABS, the outputs of GAM and GIM were multiplied by two in the weeks where $R_{\text {week }}>$ $2 \mathrm{~mm}$. These models were coded as GAM rain and GIM rain $_{\text {. }}$

Partial ROC curve analysis was used to assess the performance of the models using the pROC package for $\mathrm{R}$ (Robin et al. 2011). The presence or absence of ABS on trap plants of Fortune and Nova was considered to be the binary classification variable. The outputs of the models were evaluated as continuous estimators of the presence or 
absence of ABS on trap plants. ROC curves showed the false-positive rate (i.e., 1-specificity) on the $\mathrm{x}$-axis and the true-positive rate (i.e., sensitivity) on the y-axis across all possible cut-off thresholds for each model. Data from each orchard were analyzed separately (data not shown) and a final joint analysis including all three orchards was conducted, distinguishing between trap plants of Fortune and Nova. The AUC and pAUC between 0.9 and 1 sensitivity $\left(\mathrm{pAUC}_{0.9-1 \mathrm{se}}\right)$ were calculated by trapezoids (Jiang et al. 1996; Robin et al. 2011) and confidence intervals of $95 \%\left(\mathrm{CI}_{95}\right)$ were computed using DeLong's method (DeLong et al. 1988; Robin et al. 2011). The maximum pAUC $_{0.9-1 \text { se }}$ obtained in each cultivar was contrasted by DeLong's paired test (DeLong et al. 1988; Robin et al. 2011).

The optimal cut-off threshold was chosen among all possible outputs for each model along the 0.9 to 1 sensitivity region of the ROC curve based on the Youden's J index:

$$
J=(a d-b c) /[(a+b)(c+d)]
$$

where $a$ are true positives, $b$ are false negatives, $c$ are false positives, and $d$ are true negatives. This index maximizes the distance to the nondiscriminant (diagonal) line, with a value of zero when the model reports the same proportion of false and true positives and value unity when there are neither false positives nor false negatives (Youden 1950). Stratified bootstrap was used to calculate $\mathrm{CI}_{95}$ of 1-specificity and sensitivity for the models with their corresponding optimal cut-off thresholds (Fawcett 2006). Finally, the agreement between models and the presence or absence of $\mathrm{ABS}$ on trap plants was evaluated using Cohen's $\kappa$ index $(\kappa)$ (Cohen 1960). Values of $\kappa$ range from $\leq 0$ for a poor strength of agreement to 1 for a perfect agreement (Landis and Koch 1977).

\section{RESULTS}

Data and models. In the study of the effect of temperature and incubation time after inoculation, maximum average disease incidence was 0.74 in Fortune and 0.73 in Nova (Fig. 1A and B). The smooth terms for temperature and incubation time in GAM were significant $(P<0.0001)$ in both cultivars. When compared with the null model, the proportion of deviance accounted for by the models was 0.73 in Fortune and 0.77 in Nova. RMSE was 0.1316 and 0.1217 in Fortune and Nova, respectively. The response trend to incubation temperature was symmetrical at 20 to $25^{\circ} \mathrm{C}$ in both cultivars (Fig. $1 \mathrm{C}$ and D). The response trend to time after inoculation reached an asymptote at $30 \mathrm{~h}$ in Fortune and approximately $60 \mathrm{~h}$ in Nova (Fig. 1E and F).

When plants were inoculated under different temperature and LWD combinations, ABS symptoms were not observed on Fortune plants inoculated at $8^{\circ} \mathrm{C}$ for $8 \mathrm{~h}, 10^{\circ} \mathrm{C}$ for $10 \mathrm{~h}$ and $24 \mathrm{~h}, 20^{\circ} \mathrm{C}$ for $10 \mathrm{~h}, 30^{\circ} \mathrm{C}$ for 8 and $10 \mathrm{~h}$, and $35^{\circ} \mathrm{C}$ for $10 \mathrm{~h}$ (Fig. 2A). Disease incidence was minimal with the lowest temperatures and LWD evaluated. ABS incidence was greatest from 17 to $27^{\circ} \mathrm{C}$ with an LWD of $38 \mathrm{~h}$, reaching a maximum average value of 0.99 . Plants of

TABLE 1. Daily scores defined by the Alter-Rater model based on rainfall, leaf wetness duration (LWD), and average daily temperature (Temp) (Bhatia et al. 2003; Timmer et al. 2000)

\begin{tabular}{lccc}
\hline Rainfall $>2.5 \mathrm{~mm}$ & LWD $>10 \mathrm{~h}$ & Temp $\left({ }^{\circ} \mathrm{C}\right)$ & Score \\
\hline+ & + & $20-28$ & 11 \\
+ & + & $>28$ & 8 \\
+ & + & $<20$ & 6 \\
+ & - & $20-28$ & 6 \\
+ & - & $>28$ & 4 \\
+ & - & $<20$ & 3 \\
- & + & $20-28$ & 6 \\
- & + & $>28$ & 6 \\
- & + & $<20$ & 4 \\
- & - & $20-28$ & 3 \\
- & - & $>28$ & 0 \\
- & - & $<20$ & 0 \\
\hline
\end{tabular}

Nova were not affected when inoculated at $8^{\circ} \mathrm{C}$ for $8 \mathrm{~h}, 10^{\circ} \mathrm{C}$ for 10 $\mathrm{h}, 15^{\circ} \mathrm{C}$ for $10 \mathrm{~h}, 22^{\circ} \mathrm{C}$ for $8 \mathrm{~h}, 30^{\circ} \mathrm{C}$ for $8 \mathrm{~h}$, and $38^{\circ} \mathrm{C}$ for $16 \mathrm{~h}$ (Fig. 2B). Disease incidence followed a trend similar to Fortune but maximum values of 0.95 were recorded at $17^{\circ} \mathrm{C}$ for $38 \mathrm{~h}$ and at $20^{\circ} \mathrm{C}$ for $48 \mathrm{~h}$.

In the interrupted LWD study, mean disease incidence obtained with the continuous LWD of $20 \mathrm{~h}$ was 0.17 for Fortune (Fig. 3A) and 0.23 for Nova (Fig. 3B). At $12 \mathrm{~h} \mathrm{LWD}$, the mean incidence was 0.04 in both cultivars. Mean disease incidence with the LWD interruptions of 2 and $6 \mathrm{~h}$ were 0.04 to 0.06 with Fortune and 0.03 to 0.08 with Nova. With the LWD interruption of $1 \mathrm{~h}$, mean disease incidence was 0.18 in Fortune and 0.06 in Nova. When the data were compared with the $50 \%$ reduction of disease incidence at continuous LWD of $20 \mathrm{~h}$, there was evidence for difference in means only with the LWD interruption of $1 \mathrm{~h}$ in Fortune.

When disease incidence in plants inoculated under different temperature and LWD combinations was analyzed with GAM, the smooth terms for temperature and LWD were significant $(P<$ 0.0001 ) in both cultivars. When compared with the null model, the proportion of deviance accounted for by the models was 0.77 in Fortune and 0.82 in Nova. RMSE were 0.1545 and 0.1101 in Fortune and Nova, respectively. The model predicted disease incidence for Fortune $>0.1$ with $9^{\circ} \mathrm{C}$ and $26 \mathrm{~h}$ of LWD, $>0.3$ with $30^{\circ} \mathrm{C}$ and $25 \mathrm{~h}$ of LWD, and $>0.8$ between 16 and $27^{\circ} \mathrm{C}$ (Fig. 2C). The model predicted disease incidence in Nova was $>0.1$ with $10^{\circ} \mathrm{C}$ and $40 \mathrm{~h}$ of $\mathrm{LWD},<0.1$ with $30^{\circ} \mathrm{C}$ and $25 \mathrm{~h}$ of $\mathrm{LWD}$, and $>0.8$ between 17 and $23^{\circ} \mathrm{C}$ (Fig. 2D).

Median values and $90 \%$ credible intervals for the prior distributions of the GIM parameters were $T_{\min }=7.15^{\circ} \mathrm{C}$ (1.61 to 12.69$), T_{\text {opt }}=$ $18.78^{\circ} \mathrm{C}$ (9.95 to 27.08$), T_{\max }=28.34^{\circ} \mathrm{C}$ (19.68 to 34.33$), W_{\text {min }}=$ $25.00 \mathrm{~h}$ ( 4.30 to 45.70 ), and $W_{\max }=61.83 \mathrm{~h}$ (22.30 to 92.58). Median values and $90 \%$ credible intervals for the posterior distributions of the GIM parameters were $T_{\min }=8.51^{\circ} \mathrm{C}(2.97$ to 11.07$), T_{\text {opt }}=19.12^{\circ} \mathrm{C}$ (16.58 to 20.98$), T_{\max }=33.12^{\circ} \mathrm{C}$ (31.10 to 34.78$), W_{\min }=4.49 \mathrm{~h} \mathrm{(4.03}$ to 5.35), and $W_{\max }=15.82 \mathrm{~h}(10.56$ to 23.08$)$ for Fortune; and $T_{\min }=$ $6.15^{\circ} \mathrm{C}$ (1.73 to 9.43$), T_{\text {opt }}=20.86^{\circ} \mathrm{C}(18.90$ to 22.29$), T_{\text {max }}=34.21^{\circ} \mathrm{C}$ (32.91 to 34.94), $W_{\min }=4.36 \mathrm{~h}$ (4.02 to 5.03$)$, and $W_{\max }=51.32 \mathrm{~h}$ (13.66 to 91.51) for Nova. Posterior medians were increased by 1.8 to $20.7 \%$ for $T_{o p t}$ and $T_{\max }$ and decreased by 17 to $85.5 \%$ for $W_{\min }$ and $W_{\max }$. Posterior median of $T_{\min }$ was increased by $19.1 \%$ in Fortune and decreased by $13.9 \%$ in Nova. Similar median values and $90 \%$ credible intervals were obtained for the posterior distribution of $W_{(T)}$, with 12 to $27^{\circ} \mathrm{C}$ in both cultivars (Fig. 2E and F). However, at lower and higher temperatures, $90 \%$ credible intervals were much wider in Nova than in Fortune. Likewise, RMSE was 5.32 in Fortune and 12.91 in Nova.

Partial ROC curve analysis. The number of ABS presences or absences in trap plants exposed weekly was 12 or 52, respectively, at Alzira, 16 or 44 at Chiva, and 37 or 105 at Moncada. When ABS was present in trap plants, disease incidence in Fortune was 0.01 to 0.10 at Alzira, 0.01 to 0.41 at Chiva, and 0.02 to 0.92 at Moncada. For Nova, disease incidence was 0.03 to 0.17 at Alzira, 0.01 to 0.50 at Chiva, and 0.02 to 0.65 at Moncada.

The AUC values ranged from 0.71 with the Alter-Rater (Fig. 4A) to 0.83 with the SRS model (Fig. 4B) in Fortune, and from 0.69 with the Alter-Rater (Fig. 5A) to 0.90 with the SRS model (Fig. 5B) in Nova. Values of $\mathrm{pAUC}_{0.9-1 \mathrm{se}}$ ranged from 0.56 with the Alter-Rater model (Fig. 4A) to 0.71 with the GAM $_{\text {rain }}$ model (Fig. 4D) in Fortune, and from 0.56 with the Alter-Rater (Fig. 5A) to 0.77 with the SRS model (Fig. 5B) in Nova. The maximum value of $\mathrm{pAUC}_{0.9-1 \mathrm{se}}$ obtained in Fortune with $\mathrm{GAM}_{\text {rain }}$ was significantly higher $(P<0.05)$ than those of the AlterRater and the SRS. The maximum pAUC $0.9-1$ se obtained in Nova with the SRS model was significantly higher $(P<0.05)$ only when compared with the Alter-Rater model.

Optimal cut-off thresholds based on Youden's J index were obtained in the high-sensitivity range of 0.9 to 1 for all the models evaluated in Fortune, with the exception of the SRS (Fig. 4B). Median sensitivity with the selected cut-off thresholds ranged from 0.9 with the $\mathrm{GAM}_{\text {rain }}$ to 0.96 with the GAM in Fortune (Fig. 4D and C) and 
from 0.91 with the $\mathrm{GIM}_{\text {rain }}$ to 0.96 with the $\mathrm{GIM}_{\text {rain }}$ in Nova (Fig. 5D and F). Median values for the false-positive rate ranged from 0.41 with the GAM rain $_{\text {to }} 0.75$ with the Alter-Rater in Fortune (Fig. 4D and A) and from 0.16 with the SRS to 0.76 with the Alter-Rater in Nova (Fig. 5B and A). Values of $\kappa$ ranged from 0.1 for the Alter-Rater in both cultivars to 0.63 for the SRS in Nova.

'Fortune'

A

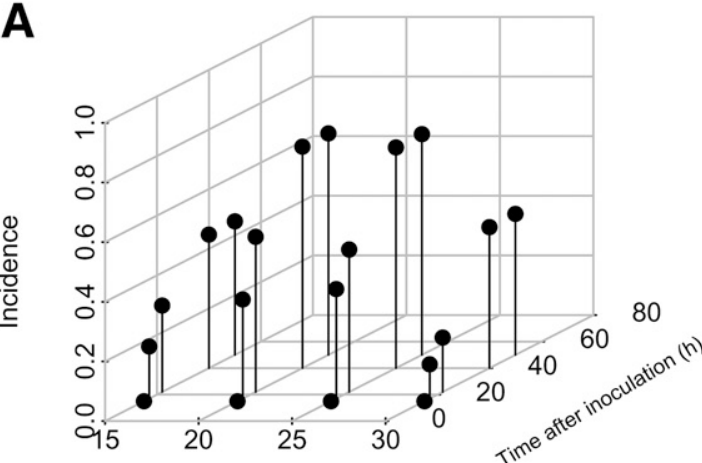

Temperature $\left({ }^{\circ} \mathrm{C}\right)$

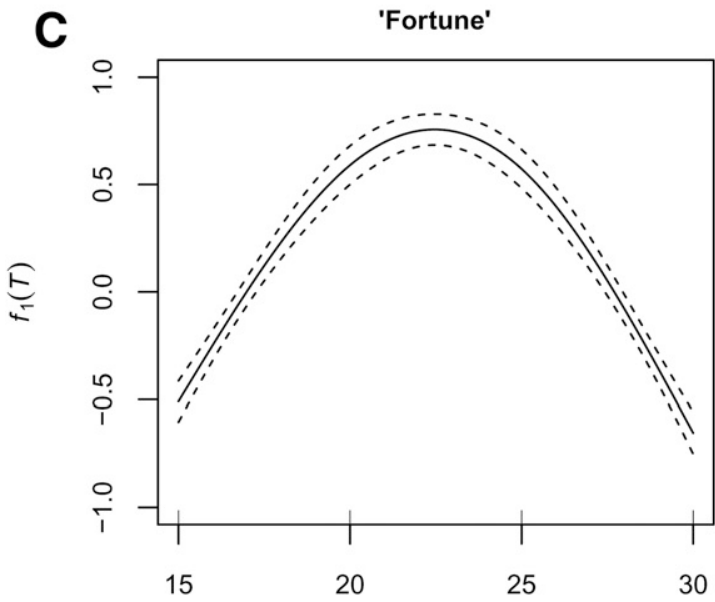

Temperature $\left({ }^{\circ} \mathrm{C}\right)$

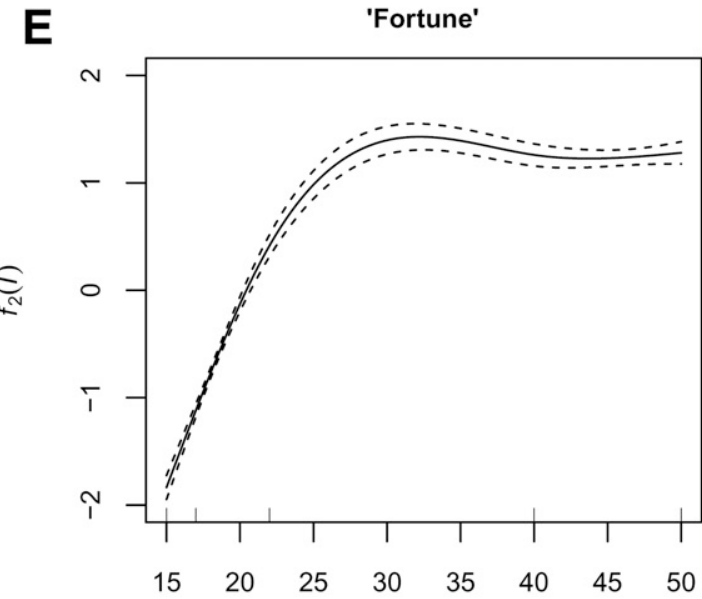

Time after inoculation $(\mathrm{h})$

\section{DISCUSSION}

Reductions in the incubation period between inoculation and symptom expression with increasing temperatures have been reported for different fungal pathogens (Chongo and Bernier 2000; Hestbjerg et al. 1994; Rossi et al. 2006; Trapero-Casas and Kaiser 1992).

'Nova'

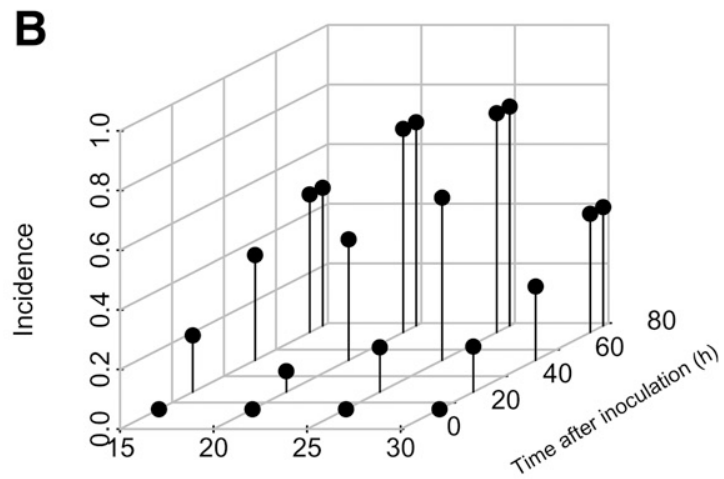

Temperature $\left({ }^{\circ} \mathrm{C}\right)$

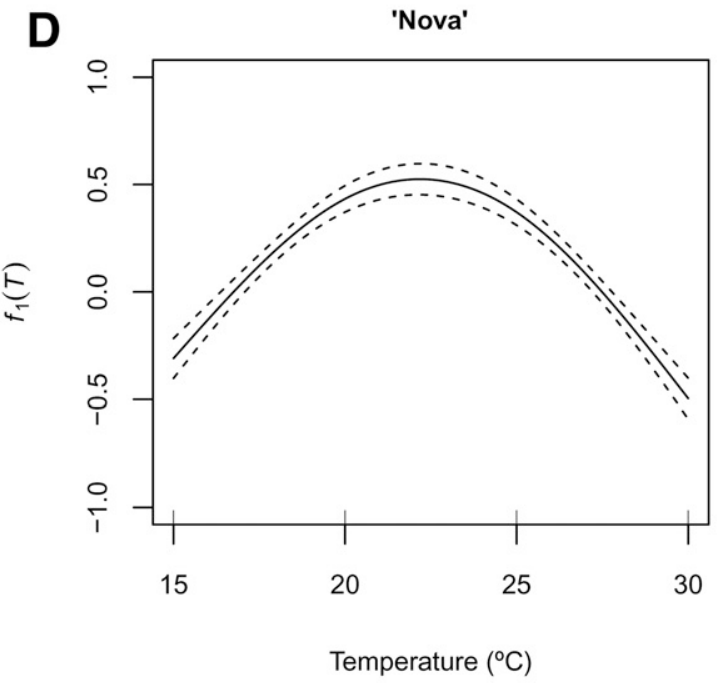

$\mathbf{F}$
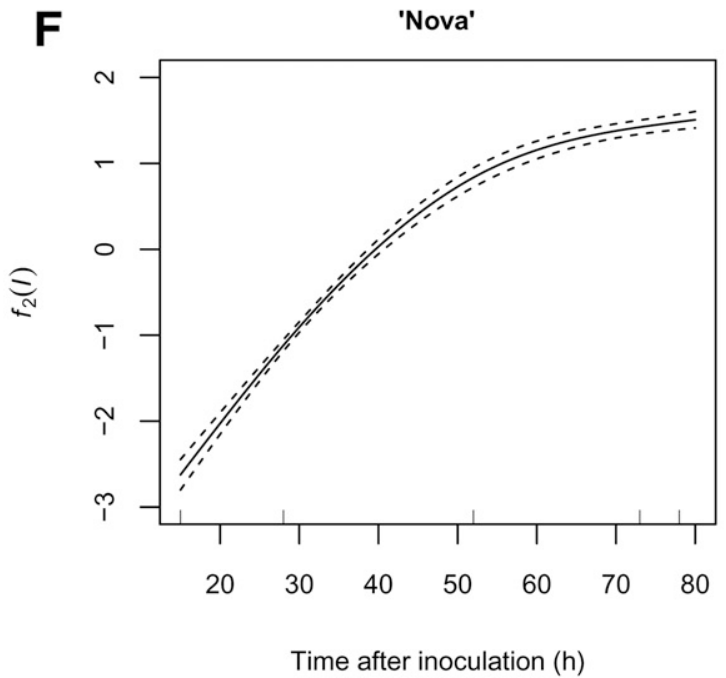

Fig. 1. Average Alternaria brown spot incidence obtained with different temperatures and times after inoculation on leaves of A, Fortune and B, Nova. Smooth terms for temperature after inoculation $\left(f_{l}(T)\right)$ estimated with generalized additive models in $\mathbf{C}$, Fortune and $\mathbf{D}$, Nova. Smooth terms for time after inoculation $\left(f_{2}(I)\right)$ in $\mathbf{E}$, Fortune and $\mathbf{F}$, Nova. Dashed lines are two times the standard errors of the estimates and upper marks along the x-axis indicate raw data. Combined data from two experiments. 
Likewise, in the present study, postinoculation temperature also had a significant negative effect on the duration of the incubation period of ABS in both cultivars. Nevertheless, maximum symptom expression was observed after no more than $30 \mathrm{~h}$ in Fortune
(Fig. 1A) and approximately $60 \mathrm{~h}$ in Nova (Fig. 1B). This short incubation period is characteristic of the ABS pathogen and other HST-producing strains of A. alternata (Timmer et al. 2003). Although the incubation period is one of the biological stages
'Fortune'

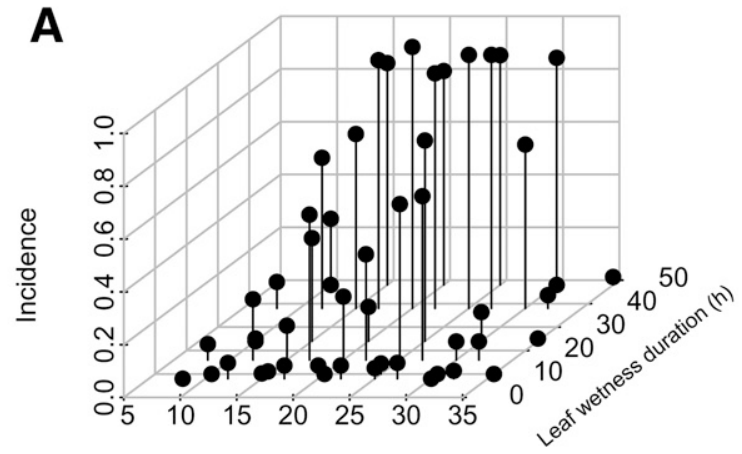

Temperature $\left({ }^{\circ} \mathrm{C}\right)$

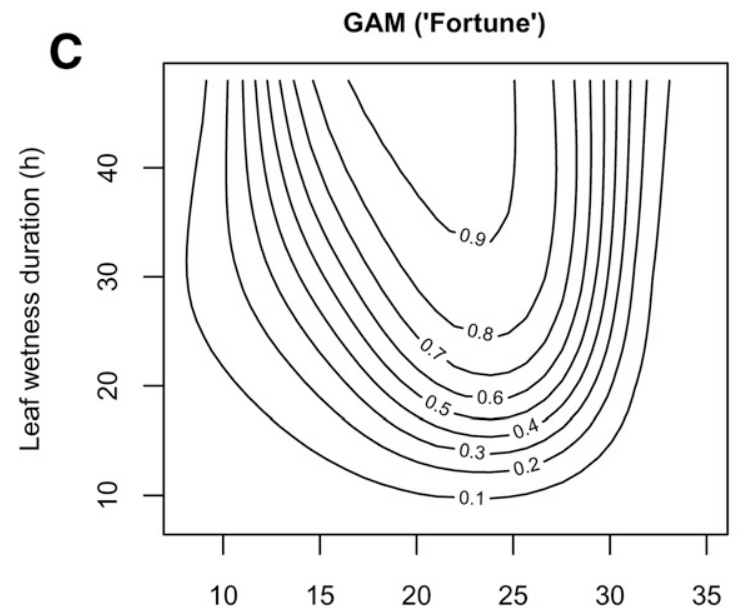

Temperature $\left({ }^{\circ} \mathrm{C}\right)$
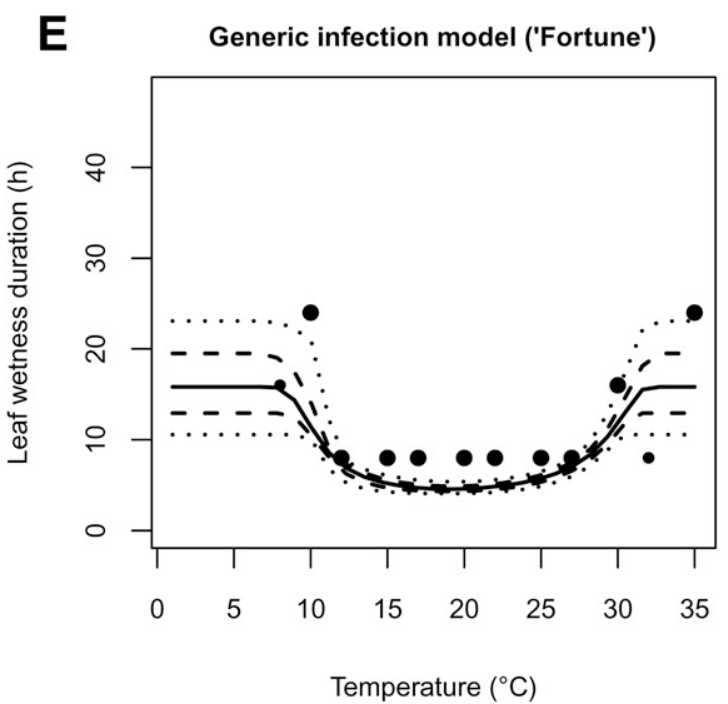

'Nova'

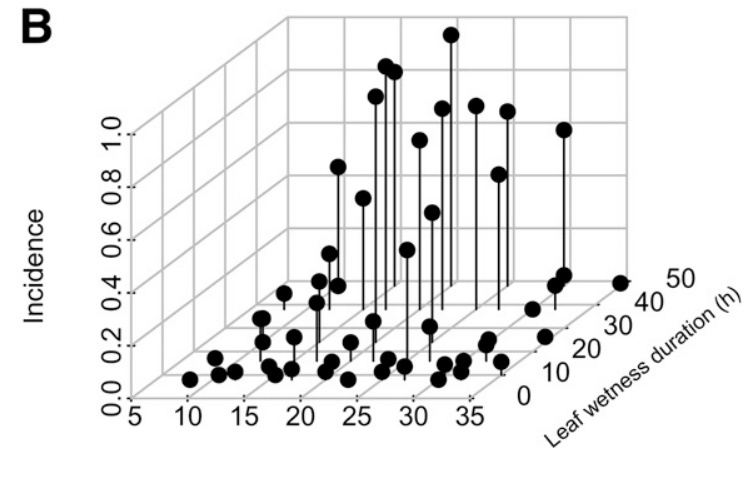

Temperature $\left({ }^{\circ} \mathrm{C}\right)$

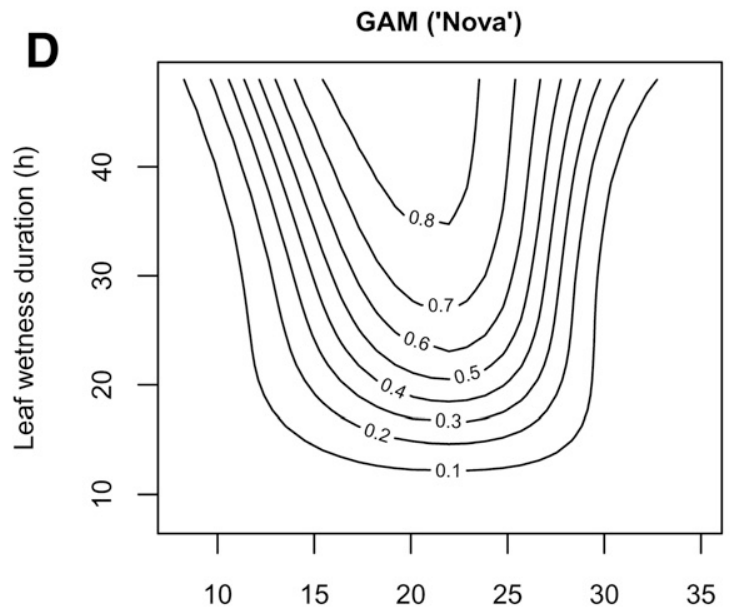

Temperature $\left({ }^{\circ} \mathrm{C}\right)$

$\mathbf{F}$

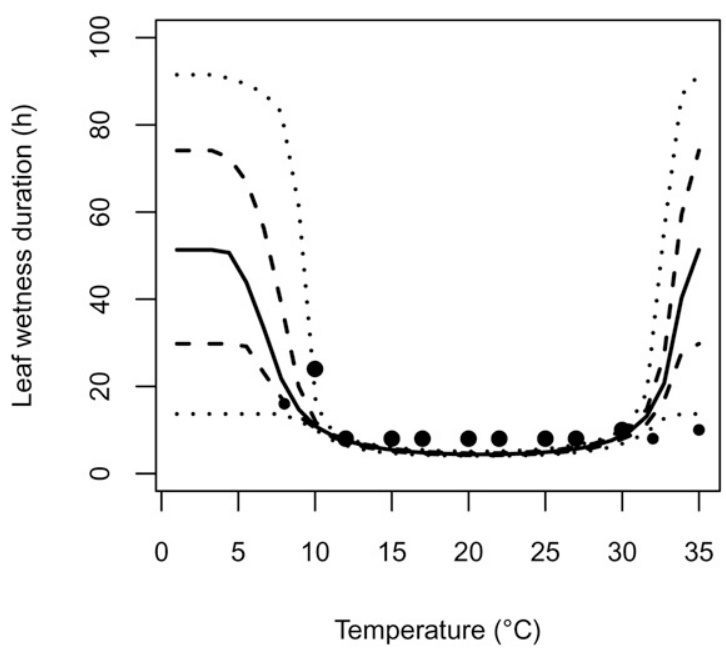

Fig. 2. Average Alternaria brown spot incidence obtained with inoculations under different temperatures and leaf wetness durations on leaves of $\mathbf{A}$, Fortune and $\mathbf{B}$, Nova. Contour plots of generalized additive model (GAM) predictions of disease incidence based on a smooth function for temperature and leaf wetness duration for C, Fortune and D, Nova. Posterior distribution of the generic infection model with 90\% credible intervals (dotted lines), first and third quartiles (dashed lines), median (solid line), and black points indicating the upper bounds of leaf wetness duration requirements for disease presence in $\mathbf{E}$, Fortune and $\mathbf{F}$, Nova. Combined data from two experiments. 
considered by disease prediction models (De Wolf and Isard 2007), it does not appear to be the critical disease cycle component for ABS prediction in this context.

Studies on the effect of interrupted LWD on the ABS pathogen were not available. Nevertheless, this topic has been extensively documented in other Alternaria pathogens. Conidia of some Alternaria spp. may survive dry periods during germination and complete the infection process after an interrupted LWD (Rotem 1994). Similarly, interruption of LWD also had a strong effect on the ABS pathogen. Disease incidence did not increase after an initial LWD of $12 \mathrm{~h}$ followed by an interruption of $1 \mathrm{~h}$ in the moderately susceptible Nova and $2 \mathrm{~h}$ in the highly susceptible Fortune (Fig. 3).

According to the classification by Magarey et al. (2005), the ABS pathogen would be considered sensitive to LWD interruption whereas other Alternaria spp. fit into the moderately sensitive group. Nevertheless, in addition to differences among species in tolerance to dryness, some key methodological issues should be taken into account. In our study, RH during LWD interruptions was set at $65 \%$, similar to field values (Bassimba et al. 2014). Although RH values have been not reported by the studies with other Alternaria spp. (Mridha and Wheeler 1993; Suheri and Price 2000; Vloutoglou et al. 1999), the infection process in the similar pathogen Stemphylium vesicarium was irreversibly stopped during LWD interruptions at $60 \% \mathrm{RH}$ but not at $96 \%$ RH (Llorente and Montesinos 2002). Furthermore, disease incidences $>0.9$ have been induced in studies with other Alternaria spp. (Mridha and Wheeler 1993; Suheri and Price 2000; Vloutoglou et al. 1999) whereas, in our study, maximum disease incidence was 0.3 (Fig. 3B), similar to the trap plants exposed in affected orchards (Bassimba et al. 2014).

Disease symptoms have been observed in detached Minneola leaves inoculated with the ABS pathogen at all temperatures evaluated between 17 and $32^{\circ} \mathrm{C}$ (Canihos et al. 1999). In our study, an LWD of $16 \mathrm{~h}$ was necessary for disease onset in Fortune and Nova at the lowest temperature evaluated $\left(8^{\circ} \mathrm{C}\right)$ (Fig. $2 \mathrm{~A}$ and $\left.\mathrm{B}\right)$, well below the minimum temperature assessed in Minneola. When disease incidence in plants inoculated under different temperature and LWD combinations was analyzed using GAM, disease incidence at low temperatures $\left(<15^{\circ} \mathrm{C}\right)$ was higher on Fortune than on Nova (Fig. $2 \mathrm{C}$ and D). Infection at suboptimal temperatures has been revealed as a key adaptive factor of ABS to semiarid Mediterranean environments (Bassimba et al. 2014). Indeed, this might be one of the features associated with the faster disease progression in Fortune than on moderately susceptible cultivars such as Nova.

The optimal temperature range for disease incidence obtained in Fortune and Nova was 20 to $25^{\circ} \mathrm{C}$ with GAM (Fig. $2 \mathrm{C}$ and D) and $20^{\circ} \mathrm{C}$ with GIM. These values are similar to the optimal range of 22 to $25^{\circ} \mathrm{C}$ reported in Minneola in Israel (Solel and Kimchi 1998) but somewhat different from the $27^{\circ} \mathrm{C}$ reported for the same cultivar in Florida (Canihos et al. 1999). Thus, a greater temperature range for infection in the isolates from Florida compared with those from Mediterranean locations might be hypothesized. Nevertheless, some key methodological factors should be considered. In the present study, 2-year-old trees of Fortune and Nova were inoculated, whereas detached leaves and 2-year-old trees of Minneola have been used in Florida and Israel, respectively. Disease severity data have been analyzed descriptively in Israel and by polynomial equations in Florida whereas, in the present study, disease incidence was analyzed by GAM and GIM. Standardized inoculations with representative collections of isolates from both humid subtropical and Mediterranean regions will be required to determine whether different temperature requirements could be associated with the diverse geographical ranges of the ABS pathogen.

Temperature and LWD functions, such as the GAM and GIM used here, are usually developed from inoculations conducted under controlled conditions which rarely go further than 24 to $48 \mathrm{~h}$ of LWD. However, due to labor and logistic constraints, these relatively short periods are seldom used in field evaluations involving the use of trap plants. Divergences between the time periods used in disease model development and evaluation may be a problem when using standard criteria of prediction quality such as the mean squared error of prediction. However, different time periods, models, and data structures are easily handled in ROC analysis because the focus is not on the overall model prediction ability but, instead, on discrimination between two mutually exclusive categories such as disease presence or absence, or values above or below a certain disease incidence or severity level. Although quantitative economic injury levels are used for integrated disease management (Zadoks 1985), a qualitative criterion of disease presence alone was preferred here due to the rigorous quality standards for ABS damage (OECD 2010). However, in other situations where commercial benchmarks are not so stringent, quantitative criteria of disease incidence or severity could also be defined when using ROC analysis.

In general, the tendency of models to over- or underestimate the disease has been usually assessed by linear regression between observed and predicted values, though this method has some limitations. Assumptions for linear regression are not always met and statistical power is seriously affected when based on a few highly variable data points (Wallach et al. 2014). The mean squared error can also be decomposed to obtain the bias term, which is positive when the model underpredicts and negative when the model overpredicts, but only on the average (Wallach et al. 2014). One advantage of ROC analysis is that it incorporates a more direct evaluation of false negatives and false positives, which can be integrated in the process of model development by means of a cost/benefit analysis (Fabre et al. 2003; Gent and Ocamb

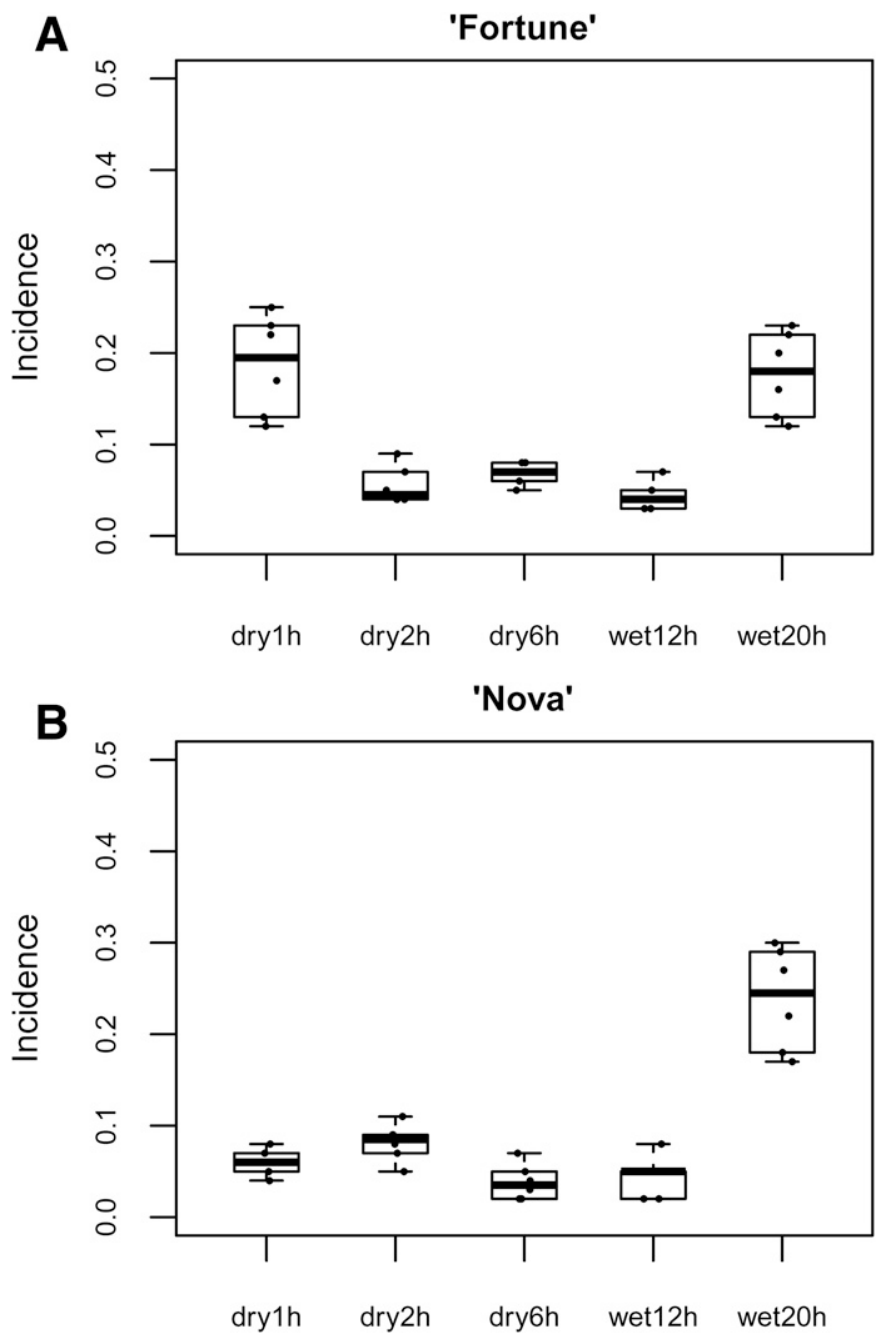

Fig. 3. Box-whisker plots of Alternaria brown spot incidence obtained with continuous leaf wetness duration of 12,20 , and $12 \mathrm{~h}+8 \mathrm{~h}$ with dry interruptions of 1,2 , and $6 \mathrm{~h}$ in leaves of $\mathbf{A}$, Fortune and $\mathbf{B}$, Nova. Combined data from two experiments. 
2009; McRoberts et al. 2011). Nevertheless, due to the stringent quality export criteria for ABS damage (OECD 2010), losses caused by false negatives far exceed the cost of unnecessary fungicide sprays due to false positives (Vicent et al. 2007).
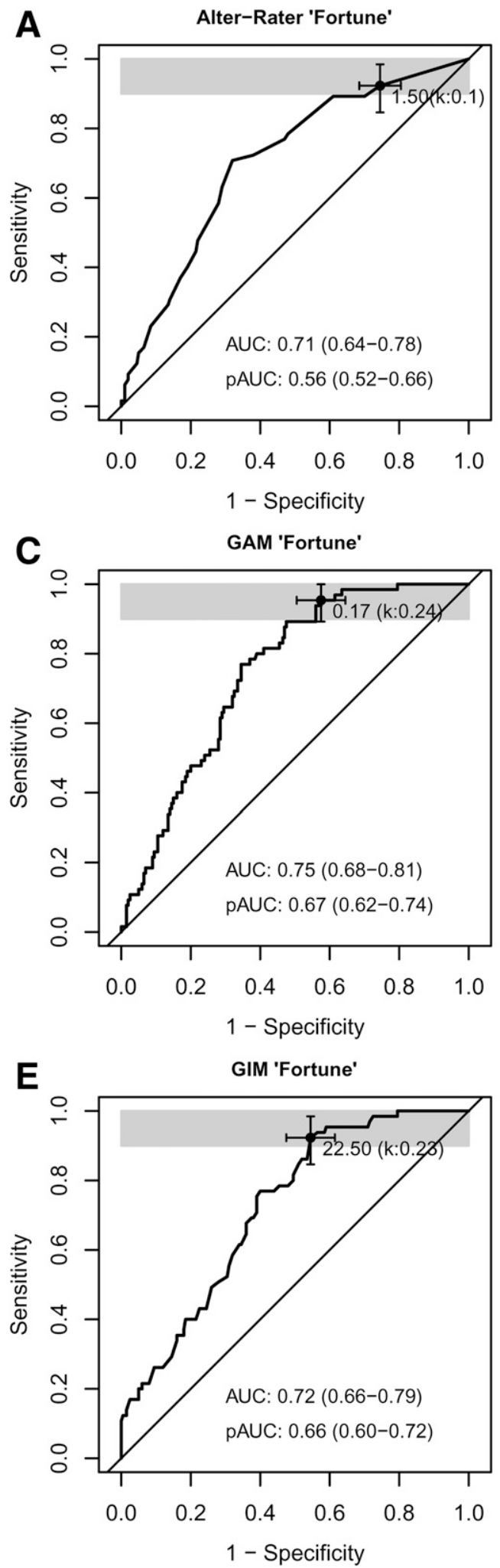

The AUC has been used extensively as a measure of model performance in ROC analysis and takes a value of 1 for a perfect model and 0.5 for a model not better than random. In this instance, AUC ranged from 0.69 with the Alter-Rater to 0.90 with the SRS in
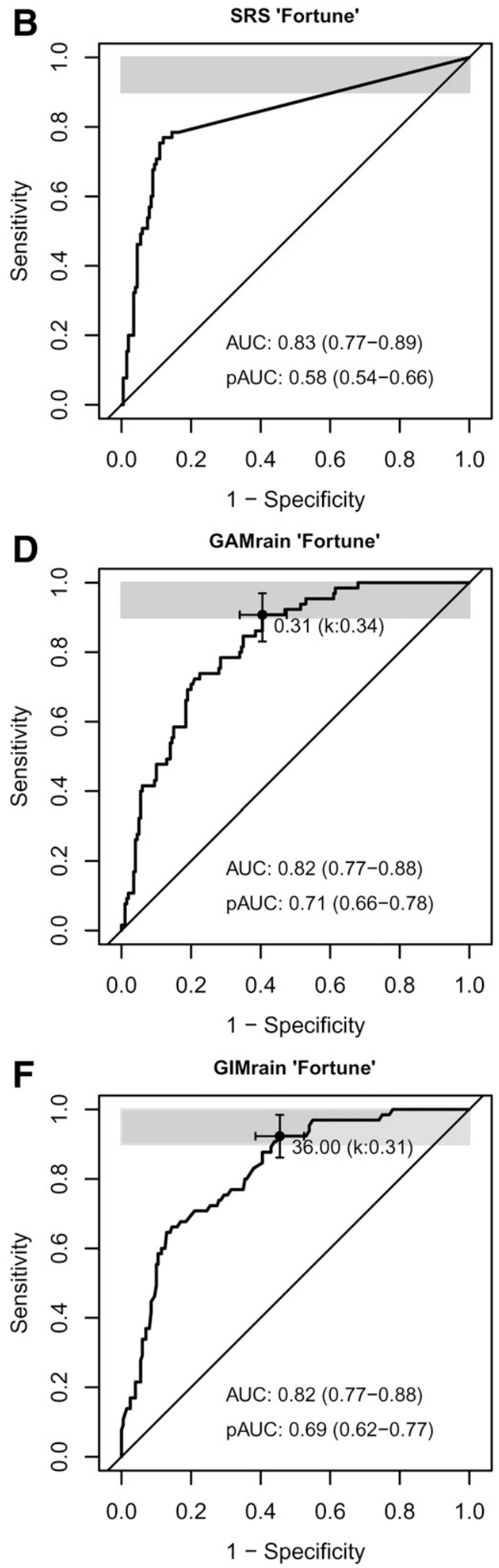

Fig. 4. Receiver-operating characteristic (ROC) plots with curve, total area under the curve (AUC), and partial AUC (pAUC) between 0.9 and 1 sensitivity with their corresponding confidence intervals of $95 \%\left(\mathrm{CI}_{95}\right)$ in Fortune obtained for $\mathbf{A}$, Alter-Rater model; $\mathbf{B}$, simple rule system (SRS); $\mathbf{C}$, generalized additive model (GAM); D, GAM with a rain factor $\left(\mathrm{GAM}_{\mathrm{rain}}\right)$; $\mathbf{E}$, generic infection model (GIM); and $\mathbf{F}$, GIM with a rain factor $\left(\mathrm{GIM}_{\text {rain }}\right)$. Dot in the ROC curve is the optimal cut-off threshold with value, Cohen's $\kappa$ index $(\kappa)$, and bars of $\mathrm{CI}_{95}$ for 1 -specificity and sensitivity. The diagonal line is the "no discrimination" line and the shadowed area is the 0.9 to 1 sensitivity region. Combined data of trap plants exposed weekly in three orchards at Alzira $(n=64)$, Chiva $(n=60)$, and Moncada $(n=$ 142) in Valencia, Spain. 
Nova (Fig. 5), significantly higher than 0.5 and similar to the values reported for other plant disease predictors (Dewdney et al. 2007; Makowski et al. 2005; Turechek and Wilcox 2005). Nevertheless, the AUC may be misleading if high sensitivity (or specificity) is a prerequisite for the models (Jiang et al. 1996; McClish 1989) as well as when ROC curves with different shapes may have similar AUC values (Wang and Chang 2011). Furthermore, it can lead to the selection of inappropriate cut-off thresholds because sensitivity and
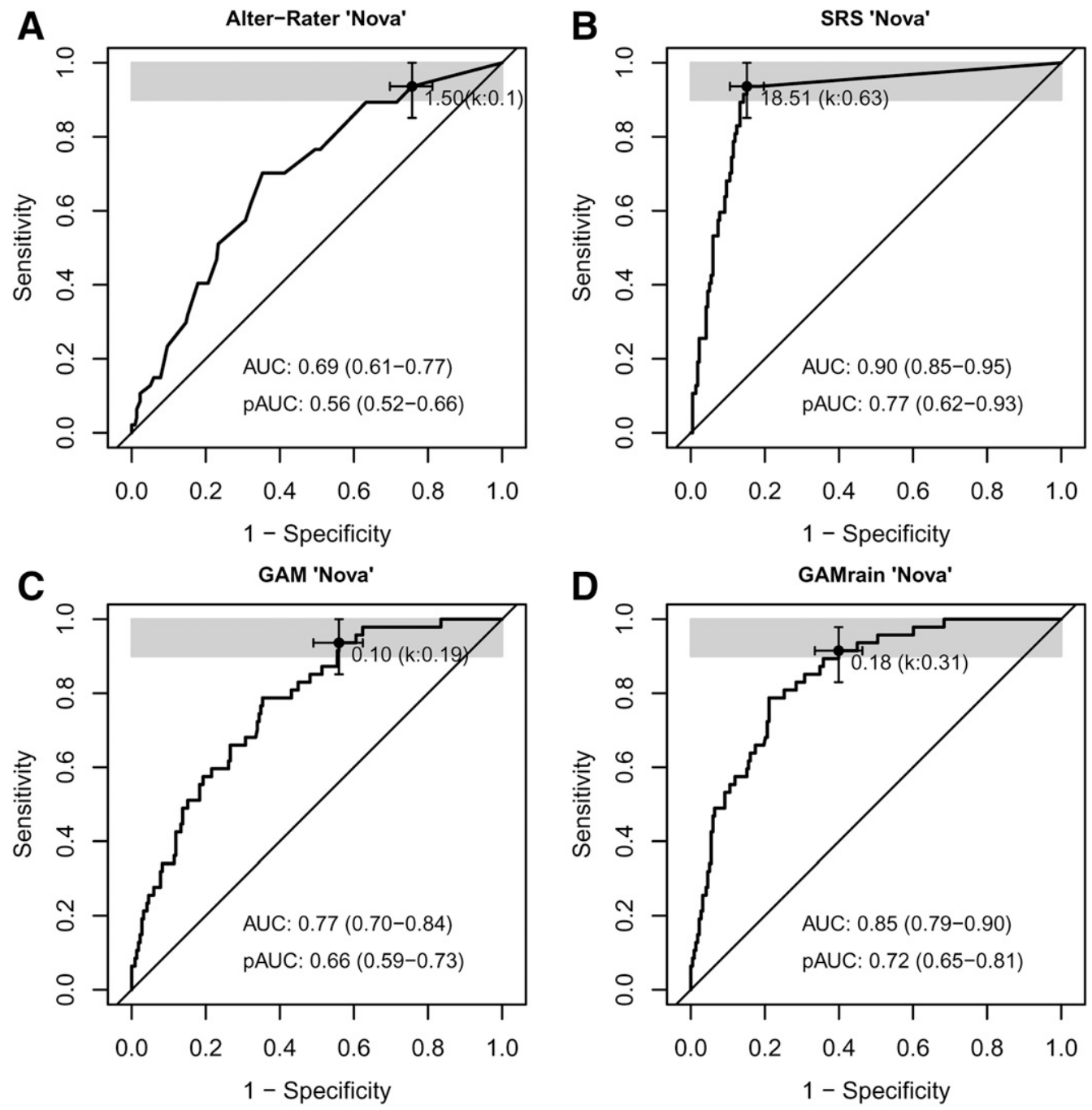

$\mathbf{E}$

GIM 'Nova'
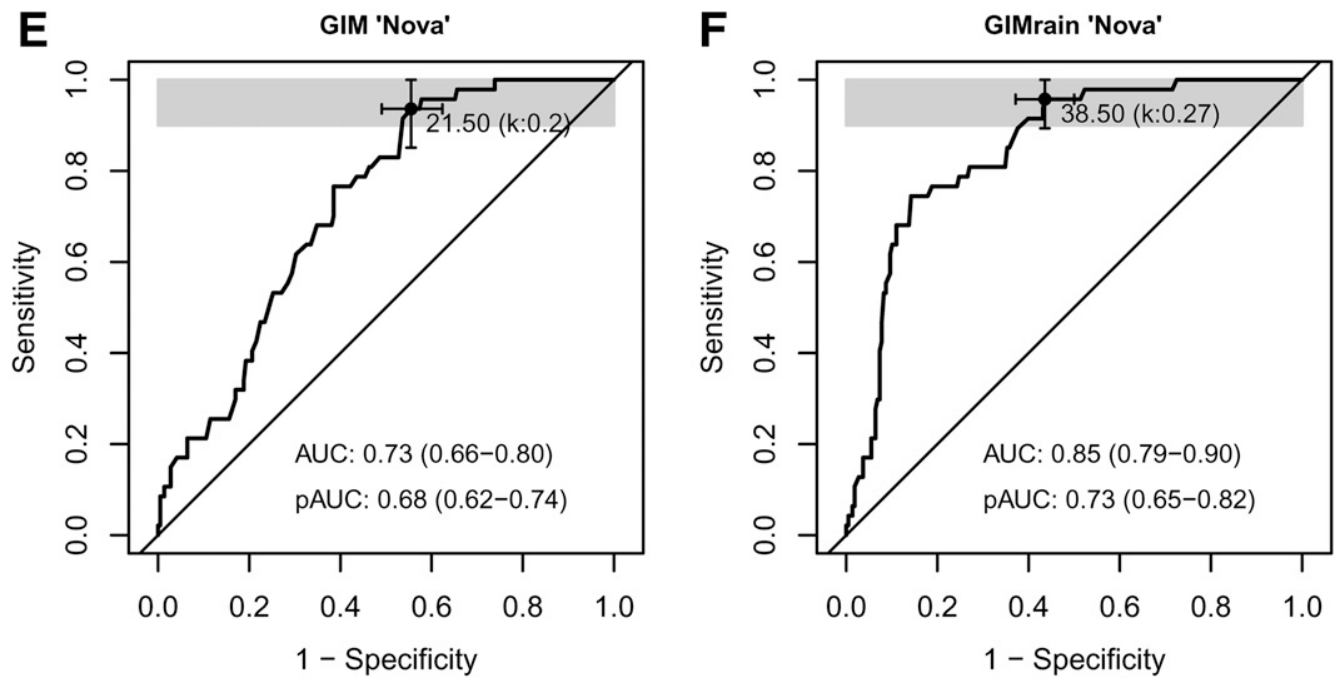

Fig. 5. Receiver-operating characteristic (ROC) plots with curve, total area under the curve (AUC), and partial AUC (pAUC) between 0.9 and 1 sensitivity with their corresponding confidence intervals of $95 \%\left(\mathrm{CI}_{95}\right)$ in Nova obtained for $\mathbf{A}$, Alter-Rater model; $\mathbf{B}$, simple rule system (SRS); $\mathbf{C}$, generalized additive model (GAM); D, GAM with a rain factor $\left(\mathrm{GAM}_{\text {rain }}\right)$; E, generic infection model (GIM); and F, GIM with a rain factor $\left(\mathrm{GIM}_{\text {rain }}\right)$. Dot in the ROC curve is the optimal cutoff threshold with value, Cohen's $\kappa$ index $(\kappa)$, and bars of $\mathrm{CI}_{95}$ for 1 -specificity and sensitivity. The diagonal line is the "no discrimination" line and the shadowed area is the 0.9 and 1 sensitivity region. Combined data of trap plants exposed weekly in three orchards at Alzira $(n=64)$, Chiva $(n=60)$, and Moncada $(n=142)$ in Valencia, Spain. 
specificity are also weighted equally by the Youden's J index. As indicated before, the analysis of pAUC would be preferred for diseases such as ABS, where models should operate in a high-sensitivity range to avoid false negatives. The definition of this sensitivity range is mostly based on expert knowledge but, considering the rigorous quality criteria for ABS (OECD 2010) and the sensitivity values reported for other plant disease models (Dewdney et al. 2007; Gent and Ocamb 2009; Makowski et al. 2005; Turechek and Wilcox 2005; Twengström et al. 1998; Yuen et al. 1996), a somewhat rigorous range between 0.9 and 1 was used in our study.

Based on the $\mathrm{pAUC}_{0.9-1 \mathrm{se}}$ values, the Alter-Rater model did not perform adequately in either of the two cultivars evaluated (Figs. 4A and 5A). This model has been developed and evaluated in Florida under humid subtropical conditions. Under semiarid Mediterranean conditions, infections of the ABS pathogen have been recorded mostly in weeks with suboptimal temperatures of 15 to $20^{\circ} \mathrm{C}$ and at least $2.5 \mathrm{~mm}$ of rainfall (Bassimba et al. 2014). However, in the AlterRater model, this combination of temperature and rainfall has one of the lowest score values (Table 1). A modification of the Alter-Rater scores may certainly improve the performance of this model in semiarid regions.

As with other fungal pathogens, disease severity induced by the ABS pathogen under different temperature and LWD combinations has been often modeled using polynomials (Canihos et al. 1999). Polynomial regression is useful when the interest of the function focuses in the vicinity of a single point. However, it may not be robust enough when the interest is over the whole domain of the function and relationships between the response variable and covariates are highly nonlinear. On the other hand, GAM used in our study incorporate nonlinear smooth functions of the covariates, which can take on a great many forms in a flexible yet robust way (Wood 2006).

As indicated before (Makowski et al. 2011), approximate Bayesian computation was particularly appropriate for fitting the GIM by Magarey et al. (2005). Originally, parameter values of the GIM have been visually estimated solely from the data but the Bayesian approach used here integrates prior knowledge of the parameters to calculate their posterior distributions, from which median and credible interval can be obtained.

In general, the modified models GAM $_{\text {rain }}$ and GIM $_{\text {rain }}$ that incorporated a rain effect outperformed their counterparts GAM and GIM. Likewise, Dewdney et al. (2007) improved model performance in arid environments by incorporating a rain effect to reduce the rate of false positives. Our results corroborate previous epidemiological studies of ABS in Spain, where virtually no disease occurred in weeks without rain, even in the presence of dew (Bassimba et al. 2014). The higher disease incidence induced by the ABS pathogen under rainy conditions compared with dew alone might be associated with the different effect of these two wetness sources on conidial release and dispersal (Timmer et al. 1998).

Optimal cut-off thresholds in the high-sensitivity region of the ROC curve were obtained in Fortune for all of the models except SRS (Fig. 4). However, $\kappa$ values indicated only a fair strength of agreement between the models and disease observations (Landis and Koch 1977). Moreover, the high false-positive rate obtained with the models would result in an unacceptable number of superfluous fungicide sprays in Fortune. Lower model performance in very susceptible cultivars compared with moderately susceptible ones have been also reported in other diseases (Dewdney et al. 2007). In Spain, Fortune has been progressively replaced because it was not possible to manage the disease even when applying exhaustive calendar spray programs. Thus, no relevant improvements in ABS management were expected by the implementation of prediction models in highly susceptible cultivars such as Fortune.

In Nova, all of the models had an optimal cut-off threshold in the high-sensitivity region of the ROC curve (Fig. 5) but only the SRS showed a substantial strength of agreement $(\kappa=0.63)$ between disease predictions and observations (Landis and Koch 1977). With the selected optimal cut-off threshold of 18.51, the SRS yielded a true-positive rate of 0.93 and a false-positive rate of 0.16 . These values were in the range of some of the best prediction models evaluated for plant diseases caused by fungi and oomycetes (Gent and Ocamb 2009; Makowski et al. 2005; Turechek and Wilcox 2005; Twengström et al. 1998).

Moderately susceptible cultivars such as Nova are widely cultivated in Spain, and calendar sprays are routinely applied for ABS management. The SRS may improve the efficiency of current fungicide schedules, allowing for targeted applications and elimination of unnecessary sprays. The high true-positive rate obtained with the SRS will be decisive for its acceptance by citrus growers, who are not prone to assume risks due to false negatives in ABS management and are more comfortable with routine calendar sprays. Another advantage of the SRS is that it only needs data of temperature and rainfall, which are commonly available. Moreover, short-range forecasts of temperature and rainfall are provided by the mesoscale model Hirlam of the Spanish State Meteorological Agency (Navascués et al. 2013). The SRS was implemented in the online platform 'gipcitricos' from IVIA at http://gipcitricos.ivia.es/avisos-alternaria.

\section{ACKNOWLEDGMENTS}

Research was funded by INIA RTA2010-00105-00-00-FEDER. A. Vicent was supported by DOC-INIA and D. D. M. Bassimba by AECID-Spain and INAGBE-Angola. We thank M. M. Dewdney and L. W. Timmer (CRECIFAS/University of Florida) for reviewing the manuscript, D. Makowski (INRA/AgroParisTech) and J. Martínez-Minaya (UV) for assistance with the approximate Bayesian computation, and the anonymous reviewers for their careful reading and helpful comments.

\section{LITERATURE CITED}

Anonymous. 2012. Informe del sector agrario valenciano. Servicio de Estudios Agrarios y Comunitarios. Consellería de Agricultura, Pesca y Alimentación. Generalitat Valenciana.

Bassimba, D. D. M., Intrigliolo, D. S., Dalla Marta, A., Orlandini, S., and Vicent, A. 2017. Leaf wetness duration in irrigated citrus orchards in the Mediterranean climate conditions. Agric. For. Meteorol. 234:182-195.

Bassimba, D. D. M., Mira, J. L., and Vicent, A. 2014. Inoculum sources, infection periods and effects of environmental factors on Alternaria brown spot of mandarin in Mediterranean climate conditions. Plant Dis. 98: 409-417.

Bhatia, A., Roberts, P. D., and Timmer, L. W. 2003. Evaluation of the AlterRater model for timing of fungicide applications for control of Alternaria brown spot of citrus. Plant Dis. 87:1089-1093.

Canihos, Y., Peever, T. L., and Timmer, L. W. 1999. Temperature, leaf wetness, and isolate effects on infection of Minneola tangelo leaves by Alternaria sp. Plant Dis. 83:429-433.

Chongo, G., and Bernier, C. C. 2000. Effects of host, inoculum concentration, wetness duration, growth stage, and temperature on anthracnose of lentil. Plant Dis. 84:544-548.

Cohen, J. 1960. A coefficient of agreement for nominal scales. Educ. Psychol. Meas. 20:37-46.

DeLong, E. R., DeLong, D. M., and Clarkepearson, D. I. 1988. Comparing the areas under two or more correlated receiver operating characteristic curves-A nonparametric approach. Biometrics 44:837-845.

Dewdney, M. M., Biggs, A. R., and Turechek, W. W. 2007. A statistical comparison of the blossom blight forecasts of MARYBLYT and cougarblight with receiver operating characteristic curve analysis. Phytopathology 97:1164-1176.

De Wolf, E. D., and Isard, S. A. 2007. Disease cycle approach to plant disease prediction. Annu. Rev. Phytopathol. 45:203-220.

Fabre, F., Dedryver, C. A., Leterrier, J. L., and Plantegenest, M. 2003. Aphid abundance on cereals in autumn predicts yield losses caused by Barley yellow dwarf virus. Phytopathology 93:1217-1222.

Fawcett, T. 2006. An introduction to ROC analysis. Pattern Recognit. Lett. 27: 861-874.

Gent, D. H., and Ocamb, C. M. 2009. Predicting infection risk of hop by Pseudoperonspora humuli. Phytopathology 99:1190-1198.

Hestbjerg, H., Wolffhechel, H., and Dissing, H. 1994. Development of Ramularia leaf spot on sugar beet as influenced by temperature and the age of the host plant. J. Phytopathol. 140:293-300.

Jiang, Y. L., Metz, C. E., and Nishikawa, R. M. 1996. A receiver operating characteristic partial area index for highly sensitive diagnostic tests. Radiology 201:745-750. 
Landis, J. R., and Koch, G. G. 1977. Measurement of observer agreement for categorical data. Biometrics 33:159-174.

Llorente, I., and Montesinos, E. 2002. Effect of relative humidity and interrupted wetness periods on brown spot severity of pear caused by Stemphylium vesicarium. Phytopathology 92:99-104.

Madden, L. V., Hughes, G., and van den Bosch, F. 2007. The Study of Plant Disease Epidemics. American Phytopathological Society Press, St. Paul, MN.

Magarey, R., Sutton, T., and Thayer, C. 2005. A simple generic infection model for foliar fungal plant pathogens. Phytopathology 95:92-100.

Magarey, R. D., and Sutton, T. B. 2007. How to create and deploy infection models for plant pathogens. Pages 3-25 in: General Concepts in Integrated Pest and Disease Management. A. Ciancio and K. G. Mukerji, eds. Springer, Dordrecht, The Netherlands.

Makowski, D., Bancal, R., and Vicent, A. 2011. Estimation of wetness duration requirements of foliar fungal pathogens with uncertain data. Application to Mycosphaerella nawae. Phytopathology 101:1346-1354.

Makowski, D., Taverne, M., Bolomier, J., and Ducarne, M. 2005. Comparison of risk indicators for Sclerotinia control in oilseed rape. Crop Prot. 24:527-531.

Marjoram, P., Molitor, J., Plagnol, V., and Tavaré, S. 2003. Markov chain Monte Carlo without likelihoods. Proc. Natl. Acad. Sci. USA 100:15324-15328.

McClish, D. K. 1989. Analyzing a portion of the ROC curve. Med. Decis. Making 9:190-195.

McRoberts, N., Hall, C., Madden, L. V., and Hughes, G. 2011. Perceptions of disease risk: From social construction of subjective judgments to rational decision making. Phytopathology 101:654-665.

Metz, C. E. 1978. Basic principles of ROC analysis. Semin. Nucl. Med. 8: 283-298.

Mridha, M. A. U., and Wheeler, B. E. J. 1993. In vitro effects of temperature and wet periods on infection of oilseed rape by Alternaria brassicae. Plant Pathol. 42:671-675.

Navascués, B., Calvo, J., Morales, G., Santos, C., Callado, A., Cansado, A., Cuxart, J., Díez, M., del Río, P., Escribà, P., García-Colombo, O., García-Moya, J. A., Geijo, C., Sánchez, E., Hortal, M., Martínez, I., Orfila, B., Parodi, J. A., Rodríguez, E., Sánchez-Arriola, J., Santos-Atienza, I., and Simarro, J. 2013. Long-term verification of HIRLAM and ECMWF forecasts over Southern Europe: History and perspectives of Numerical Weather Prediction at AEMET. Atmos. Res. 125-126:20-33.

OECD. 2010. International Standards for Fruit and Vegetables: Citrus Fruit. Organisation for Economic Co-Operation and Development (OECD), Paris.

Peres, N. A., and Timmer, L. W. 2006. Evaluation of the Alter-Rater model for spray timing for control of Alternaria brown spot on Murcott tangor in Brazil. Crop Prot. 25:454-460.

R Core Team. 2013. R: A Language and Environment for Statistical Computing. R Foundation for Statistical Computing, Vienna.

Reis, R. F., de Goes, A., Mondal, S. N., Shilts, T., Brentu, F. C., and Timmer, L. W. 2006. Effect of lesion age, humidity, and fungicide application on sporulation of Alternaria alternata, the cause of brown spot of tangerine. Plant Dis. 90:1051-1054.

Robin, X., Turck, N., Hainard, A., Tiberti, N., Lisacek, F., Sanchez, J. C., and Müller, M. 2011. pROC: An open-source package for $\mathrm{R}$ and $\mathrm{S}$ plus to analyze and compare ROC curves. BMC Bioinf. 12:77.

Rossi, V., Bolognesi, M., Languasco, L., and Giosuè, S. 2006. Influence of environmental conditions on infection of peach shoots by Taphrina deformans. Phytopathology 96:155-163.
Rotem, J. 1994. The Genus Alternaria. Biology, Epidemiology and Pathogenicity. American Phytopathological Society Press, St. Paul, MN.

Solel, Z., and Kimchi, M. 1998. Histopathology of infection of Minneola tangelo by Alternaria alternata pv. citri and the effect of host and environmental factors on lesion development. J. Phytopathol. 146:557-561.

Stewart, J. E., Timmer, L. W., Lawrence, C. B., Pryor, B. M., and Peever, T. L. 2014. Discord between morphological and phylogenetic species boundaries: Incomplete lineage sorting and recombination results in fuzzy species boundaries in an asexual fungal pathogen. BMC Evol. Biol. 14:38.

Suheri, H., and Price, T. V. 2000. Infection of onion leaves by Alternaria porri and Stemphylium vesicarium and disease development in controlled environments. Plant Pathol. 49:375-382.

Timmer, L. W., Darhower, H. M., Zitko, S. E., Peever, T. L., Ibañez, A. M., and Bushong, P. M. 2000. Environmental factors affecting the severity of Alternaria brown spot of citrus and their potential use in timing fungicide applications. Plant Dis. 84:638-643.

Timmer, L. W., Peever, T. L., Solel, Z., and Akimitsu, K. 2003. Alternaria diseases of citrus-Novel pathosystems. Phytopathol. Mediterr. 42:3-16.

Timmer, L. W., Solel, Z., Gottwald, T. R., Ibañez, A. M., and Zitko, S. E. 1998. Environmental factors affecting production, release, and field populations of conidia of Alternaria alternata, the cause of brown spot of citrus. Phytopathology 88:1218-1223.

Trapero-Casas, A., and Kaiser, W. J. 1992. Influence of temperature, wetness period, plant age, and inoculum concentration on infection and development of Ascochyta blight of chickpea. Phytopathology 82:589-596.

Turechek, W. W., and Wilcox, W. F. 2005. Evaluating predictors of apple scab with receiver operating characteristic curve analysis. Phytopathology 95: 679-691.

Twengström, E., Sigvald, R., Svensson, C., and Yuen, J. 1998. Forecasting Sclerotinia stem rot in spring sown oilseed rape. Crop Prot. 17:405-411.

Vicent, A., Armengol, J., and García-Jiménez, J. 2007. Rain fastness and persistence of fungicides for control of Alternaria brown spot of citrus. Plant Dis. 91:393-399.

Vicent, A., Badal, J., Asensi, M. J., Sanz, N., Armengol, J., and García-Jiménez, J. 2004. Laboratory evaluation of citrus cultivars susceptibility and influence of fruit size on Fortune mandarin to infection by Alternaria alternata pv. citri. Eur. J. Plant Pathol. 110:245-251.

Vloutoglou, I., Fitt, B. D. L., and Lucas, J. A. 1999. Infection of linseed by Alternaria linicola; effects of inoculum density, temperature, leaf wetness and light regime. Eur. J. Plant Pathol. 105:585-595.

Wallach, D., Makowski, D., Jones, J. W., and Brun, F. 2014. Model evaluation. Pages 345-406 in: Working with Dynamic Crop Models, 2nd ed. Methods, Tools and Examples for Agriculture and Environment. D. Wallach, D. Makowski, J. W. Jones, and F. Brun, eds. Academic Press, San Diego, CA.

Wang, Z., and Chang, Y. C. I. 2011. Marker selection via maximizing the partial area under the ROC curve of linear risk scores. Biostatistics 12: 369-385.

Wood, S. 2006. Generalized Additive Models: An Introduction with R. Chapman and Hall/CRC, Boca Raton, FL.

Youden, W. J. 1950. Index for rating diagnostic tests. Cancer 3:32-35.

Yuen, J., Twengström, E., and Sigvald, R. 1996. Calibration and verification of risk algorithms using logistic regression. Eur. J. Plant Pathol. 102:847-854.

Zadoks, J. C. 1985. On the conceptual basis of crop loss assessment-The threshold theory. Annu. Rev. Phytopathol. 23:455-473. 